\title{
A comparative case study of cultivated land changes in Fujian and Taiwan
}

\author{
Jian-fei Chen ${ }^{\mathrm{a}}$, Su-qiong Wei ${ }^{\mathrm{b}}$, Kang-tsung Chang ${ }^{\mathrm{c}, *}$, Bor-wen Tsai ${ }^{\mathrm{d}}$ \\ ${ }^{a}$ College of Geographical Sciences, Guangzhou University, Guangzhou 510405, China \\ ${ }^{\mathrm{b}}$ College of Geographical Sciences, Fujian Normal University, Fuzhou 350007, China \\ ${ }^{\mathrm{c}}$ Department of Geography, National Taiwan University, Taipei, 106, Taiwan \\ ${ }^{\mathrm{d}}$ Department of Geography, National Taiwan University, Taipei, 106, Taiwan
}

Received 10 June 2005; received in revised form 10 November 2005; accepted 11 May 2006

\begin{abstract}
In this study we chose Fujian and Taiwan for a comparative case study of cultivated land changes. Separated by a short strait, these two regions are similar in biophysical and cultural characteristics but differ in the level of economic development. Taiwan is ahead of Fujian by 15 to 20 years in economic development. We compared quantitative and qualitative changes of cultivated land in these two regions, and analyzed the proximate causes and the driving forces for cultivated land changes over time. The study showed a time lag, similar to that of economic development, in the dynamic (i.e., greater rates of change) period of cultivated land changes and the ranking of major driving forces. The results suggest that similar land-use changes can occur in different regions as the regions pass through comparable stages of economic development at different times.
\end{abstract}

(C) 2006 Elsevier Ltd. All rights reserved.

Keywords: Cultivated land; Land-use change; Driving forces; Fujian; Taiwan

\section{Introduction}

Several international study groups on land-use/landcover change (LUCC), including the International Geographical Union (IGU), the International GeosphereBiosphere Programme (IGBP), and the International Human Dimensions Programme (IHDP), have advocated in recent years the importance of comparative case studies. According to these groups, comparative case studies can greatly improve our understanding of the major human causes of LUCC in different geographic and historical contexts. For example, Geist and Lambin (2002) compared 152 local case studies from Asia, Africa, and Latin America in search for a general understanding of the proximate causes and underlying driving forces of tropical deforestation. Instead of finding a general theory, they concluded

\footnotetext{
*Corresponding author.

E-mail addresses: cjf@gzhu.edu.cn (J.-f. Chen), suqiongwei@126.com (S.-q. Wei), ktchang@ntu.edu.tw (K.-t. Chang), tsaibw@ntu.edu.tw (B.-w. Tsai).
}

that tropical forest decline is determined by different combinations of factors in varying geographic and historical contexts. Geist and Lambin (2002) highlight the challenge of finding any general theories for LUCC and, at the same time, the importance of comparative case studies. But there are both conceptual and practical difficulties in comparing LUCC in different regions. The conceptual difficulty lies in the coordination of time, space, and human driving forces in different regions. And the practical difficulty lies in data availability and reliability and, for comparative analysis, data compatibility.

Most LUCC researchers recognize economic development as perhaps the most basic driving force for land-use changes (e.g., Heilig, 1997). In this study, we linked economic development to a comparative case study by assuming that similar land-use changes can occur in different regions as the regions pass through comparable stages of economic development at different times. To test the feasibility of our assumption, we chose to analyze and compare changes of cultivated land in Taiwan and Fujian. 
Separated by a short strait, Taiwan and Fujian are similar in biophysical characteristics as well as demographic and cultural characteristics. But the two regions differ in the political system and the level of economic development. Since adopting the open-door policy in 1978, China has developed an export-oriented economy, similar to her neighbors such as Taiwan and South Korea (World Bank, 1993; Liou, 1999). Thus the difference in the political system, except for land management policies, is not really a major factor in this comparative study. Economic development is different: Taiwan has prospered since the 1960s, whereas Fujian began its economic development only after China's open-door policy in 1978. There is a time lag of 15-20 years. We are therefore interested in finding whether this time lag is repeated in cultivated land changes of the two regions. Cultivated land, also called farmland, refers to land under temporary and permanent crops; in both Taiwan and Fujian, cultivated land can generally be classified into paddy field and upland field. As a land use, cultivated land may increase in the initial stage of economic development but invariably decreases as increased population, urbanization, industrialization, road construction, and nonstaple food production demand more space. In other words, change (i.e., decline) of cultivated land is closely related to the overall pattern of economic development and is thus a good indicator for testing our assumption.

This paper is organized into the following sections. Section 2 describes Fujian and Taiwan in terms of their physical environment, cultural and demographic characteristics, economic development, and land management policies. Section 3 compares quantitative and qualitative measures of cultivated land changes in the two regions. Section 4 explains the proximate causes and explores the driving forces for cultivated land changes in Fujian and Taiwan. Section 5 discusses the results and concludes the paper.

\section{Study areas}

\section{Physical environment}

Fujian has a total area of $121,400 \mathrm{~km}^{2}$. About $75 \%$ of the land area in Fujian is covered by mountainous terrain, $15 \%$ is classified as hilly lands, and only $10 \%$ is lowlands, which are limited to the coastal area and small alluvial valleys (Edmonds, 1996). Lying almost directly across the Taiwan Strait from Fujian is Taiwan. With a total land area of $36,000 \mathrm{~km}^{2}$, Taiwan is less than one-third of Fujian in size (Fig. 1). About $47 \%$ of the land area in Taiwan is classified as highlands (above $1000 \mathrm{~m}$ ), 27\% slopelands $(100-1000 \mathrm{~m}$ ), and $26 \%$ lowlands (below $100 \mathrm{~m}$ ). Only lowlands, which are mainly on the alluvial plains of the west coast, are suitable for agricultural use. The land surface is very steep, with nearly $50 \%$ of the island having slopes above $40 \%$. Both Fujian and Taiwan are limited in land areas suitable for cultivation. In terms of climate,

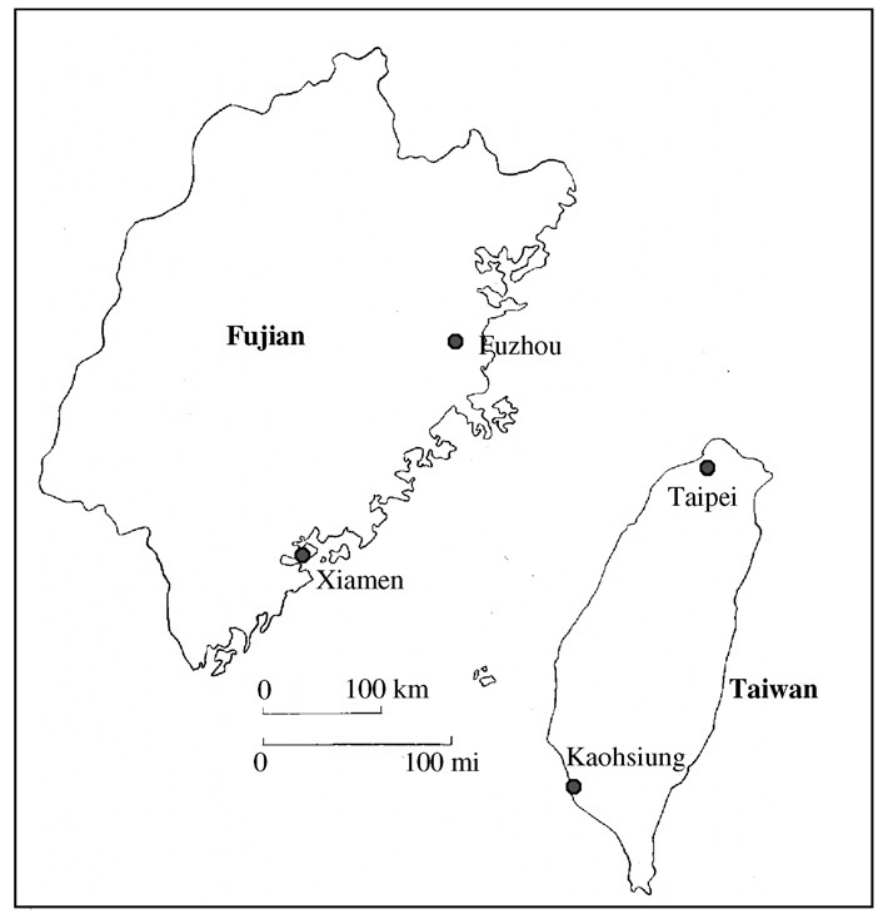

Fig. 1. Taiwan and Fujian across the Taiwan Strait.

Fujian has a subtropical monsoon climate and Taiwan a subtropical and tropical monsoon climate. Warm temperature and ample precipitation bring double or triple agricultural harvests annually to both regions.

\section{Cultural and demographic characteristics}

Fujian and Taiwan have similar cultural and demographic characteristics. Northern Chinese culture spread to Fujian with three major southward migrations of han people in history. Fujianese culture, a localized han ethnic culture, extended to Taiwan and gradually became the main component of Taiwanese culture (Liu, 2002). About $80 \%$ of people in Taiwan are descendants of immigrants from Fujian.

\section{Economic development}

Taiwan's economic development began in the 1960s when the Taiwan government adopted an export orientation policy to promote labor-intensive industries (Lin, 1973; Ho, 1978; Ranis, 1979; Kuo, 1983). The first export processing zone was established in Kaohsiung in 1966, followed by two more in 1969. A shift from labor-intensive to capital- and technology-intensive industries in Taiwan's economy took place in the 1970s and 1980s (Kuo, 1983; Gold, 1986). In 1973 the Taiwan government selected petrochemical, basic metal, and shipbuilding industries for major construction projects in the public sector. Later the government promoted computers, telecommunication, and precision instrument and machinery for industrial upgrade. In 1980 the first science-based industrial park was 
established in Hsinchu ( $\mathrm{Li}$, 1995). The shift toward knowledge-based, high-tech industries continued into the 1990s (Chen and Lee, 2004). Taiwan has become a leading producer of semiconductors, computers and computer peripherals, and telecommunication equipment in the world.

In 1978 China began an open-door policy for economic "modernization" along the coastal areas. Fujian has been an important part of this coastal strategy. The open-door policy encouraged the development of small-scale, laborintensive township and village enterprises (TVEs) as well as the growth of foreign-invested and private enterprises in the industrial, transportation, and construction sectors (Lin, 1992; Yabuki, 1995; Chen, 1998; Otsuka et al., 1998; Oi, 1999; Yeung, 2005). The Xiamen Special Economic Zone (SEZ) was established in 1979, followed by the Fuzhou Mawei Economic and Technical Development Zone (ETDZ) in 1985 and the Fuqing Bay Investment District in 1992 (Fan, 1995; Yeung and Chu, 2000). With substantial foreign investment from Taiwan, Hong Kong, and overseas Chinese in Southeast Asia, Xiamen and Fuzhou have become important growth centers in South China and Fujian one of the five "emerging tigers" in China's coastal provinces (Weng, 1994; Ash and Qi, 1996; Liou, 1999; Howell, 2000).

The average growth of GDP in Fujian was 13.9\% between 1978 and 1998, making it China's fastest growing province (Golley, 2002). Fujian's per capita GDP relative to national average was 0.72 in 1978 and 1.63 in 2002. In 2002 Fujian's per capita GDP was USD 1630. (As a comparison, Taiwan's per capita GDP in 2002 was USD 12,600.) Leathers and furs, wood products, paper and products, plastic products, and clothing dominated $\mathrm{Fu}$ jian's manufacturing sector from the mid-1980s to the mid1990s (Golley, 2002). According to Chen (1998), light industry products accounted for $68 \%$ of export commodities in 1995, while heavy industry products and agricultural products accounted for $20 \%$ and $12 \%$, respectively. In recent years, the Fujian government has targeted petrochemicals, machinery and electronics, building materials, forest products, and fisheries as five leading industries to promote (Maruya, 2000). This process of industrial upgrade and structural change is in many ways similar to Taiwan's experience during the 1970s, with a time lag of 15 to 20 years.

\section{Rural land management policies}

China's constitution stipulates that land in rural areas is collectively owned by rural residents. Since 1978, the Chinese government has made a number of changes to the rural land system and land development processes (Kirkby and Zhao, 1999; Cartier, 2001; Zhai and Huang, 2002; de Brauw et al., 2004; Lin and Ho, 2005). The introduction of the household production responsibility system in 1978, followed by the replacement of the commune system by a township and village system in 1983, decentralized the decision-making process in agricultural production and allowed farmers to engage in a variety of nonagricultural activities. Starting in 1983, the TVEs grew rapidly and became an important source of China's economic growth (Eng, 1997; Johnson and Woon, 1997; Kirkby and Zhao, 1999; Fan et al., 2003). At the same time, these nonagricultural activities, along with urban expansion, resulted in a severe loss of cultivated land during the years 1984-1986 (Ash and Edmonds, 1998; Lin and Ho, 2005).

To slow down the loss of cultivated land, China enacted the Land Management Law and created the Land Administration Bureau in 1986. The new law decelerated the shrinkage of arable land for several years, but the process of conversion began to accelerate again after 1990, primarily because of the relatively higher incomes to be derived from nonagricultural activities (Kirkby and Zhao, 1999; Lin and Ho, 2005). The promulgation of the "Regulation for the Protection of Basic Farmland" in 1994 prohibited the removal of "basic farmland" from cultivation. This was followed by a one-year moratorium on arable land conversion in 1997, which was later extended to 1999. In 1998, China revised the Land Management Law by requiring each province to designate at least $80 \%$ of its cultivated land as "basic farmland," which must be preserved. But the new law is still subject to local manipulation and internal contradictions (Cartier, 2001; Lin and Ho, 2005).

Taiwan's rural land management policies began with a series of land reform programs in 1949-1953. The "37.5\% Rent Reduction Act" set the farm rental rate at $37.5 \%$ of the annual yield of the main crop; the "Sale of Public Lands Act" sold off a large area of public lands; and the "Land to the Tiller Act" allowed each landlord to keep only 3 chia ( 1 chia $=0.97$ hectares $)$ of medium-grade paddy field or 6 chia of dry land (Ho, 1978). Although these land reform programs significantly raised the level of land ownership among farmers, they also resulted in a large number of small holders.

Problems with labor-intensive small-scale farming operations began to appear during the 1960s as Taiwan's export-oriented industries provided job opportunities outside of agriculture (Thorbecke, 1992). Farm income per capita deteriorated compared to nonfarm income, and mechanization for improving agricultural productivity was hampered by the small average size of a family farm (Clark, 1989; Thorbecke, 1992). In 1973, Taiwan enacted the "Agricultural Development Act," which eventually became the body of laws governing Taiwan's rural land management. To promote agricultural mechanization in the 1970s, the Act pushed for increasing the "operational" farm size through joint operations and cooperative farming without affecting the ownership pattern. Starting in the late 1980s, a number of policy changes for liberalization of agriculture have been introduced to the Agricultural Development Act. The concept that agricultural land is owned by tillers and reserved for agricultural use has been gradually redefined to allow agricultural land to be traded in the 
free land market and to be converted for nonagricultural uses. In 1995, the Taiwan government implemented the "Agricultural Land Release Act," allowing over 300,000 hectares (ha) of secondary agricultural land to be converted for nonagricultural use.

\section{Measures of cultivated land changes}

\section{Quantitative measures}

Fig. 2 shows the decline of Fujian's cultivated land since 1975. The pattern resembles the national trend for the period 1978-1995: a steep decrease in 1984-1986, a slower decrease in 1987-1990, and another steep decline in 1991-1995. After 1996 and the change of method for compiling agricultural statistics, Fig. 2 shows a rapid rate of decrease. In quantitative terms, the average annual rate of decrease from 1996 to 2001 was 17,696 ha, considerably higher than 5488 ha from 1980 to 1989 and 5755 ha from 1990 to 1995. Fujian's cultivated land totaled 1.17 Mha (million hectares) in 2001 (Fujian Province Statistics Bureau, 2002).

Taiwan's cultivated land totaled 848,743 ha in 2001 (Council of Agriculture, 2002). Fig. 2 shows gradual and steady decreases of cultivated land mainly after 1977 . The average annual rate of decrease was 2140 ha from 1978 to 1989 and 3822 ha from 1990 to 2001. Although the rate of decrease did increase over time in Taiwan, the rate was slower than that of Fujian, especially in recent years.

Fig. 3 shows changes of cultivated land per capita. It declined from 0.06 to 0.03 ha between 1975 and 2000 in Fujian and from 0.06 to 0.04 ha in Taiwan during the same period. Although the two regions have similar changes of cultivated land per capita, they differ in terms of cultivated land per farm labor (Fig. 3). In Fujian cultivated land per farm labor dropped from 0.07 to 0.05 ha between 1975 and 2000 , whereas in Taiwan it actually increased slightly from 0.16 to 0.23 ha during the same period. This difference can be attributed to a greater absorption rate of farm labor in other economic sectors in Taiwan as well as a series of aforementioned land reform policies.

\section{Qualitative measures}

Qualitative changes of cultivated land are equally as important as quantitative changes. To measure cultivated land productivity, we adopted the cultivated land standard index (CLSI), an index proposed by Zheng and Feng

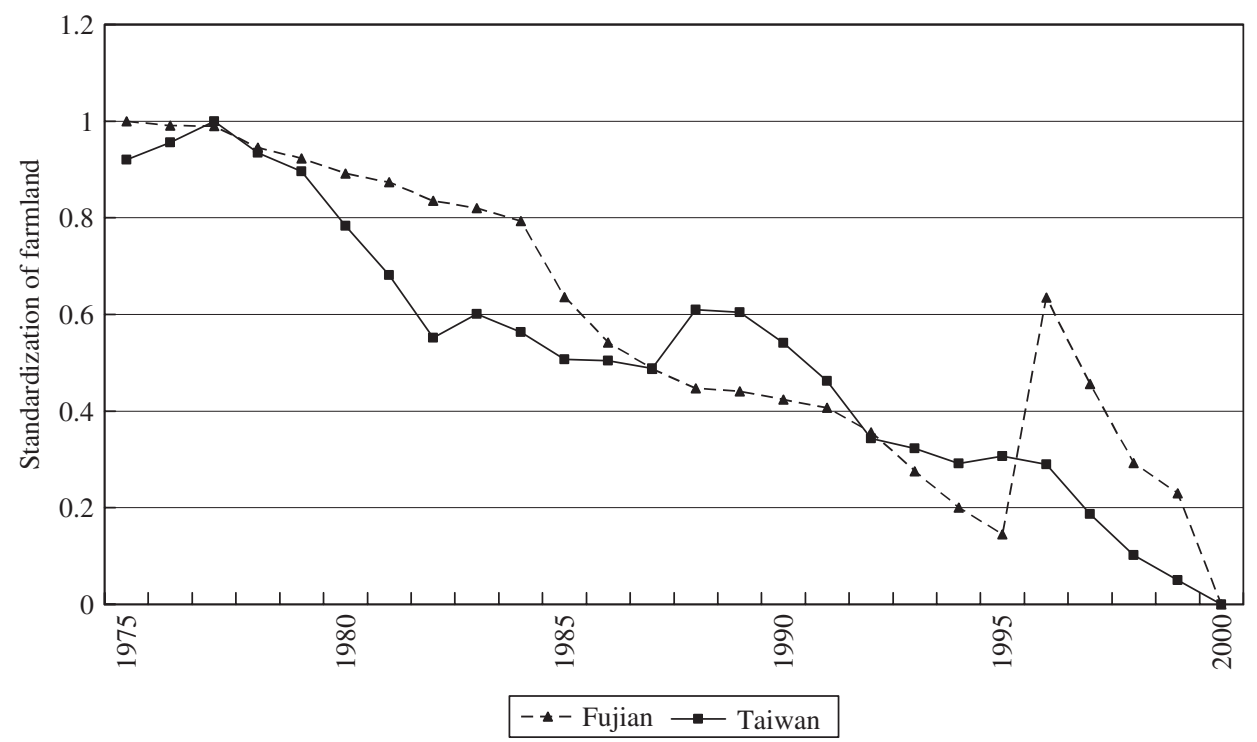

Fig. 2. Farmland in Fujian and Taiwan, 1975-2000. For the purpose of comparison between the two regions, areas of cultivated land have been standardized to the scale of $0.0-1.0$.
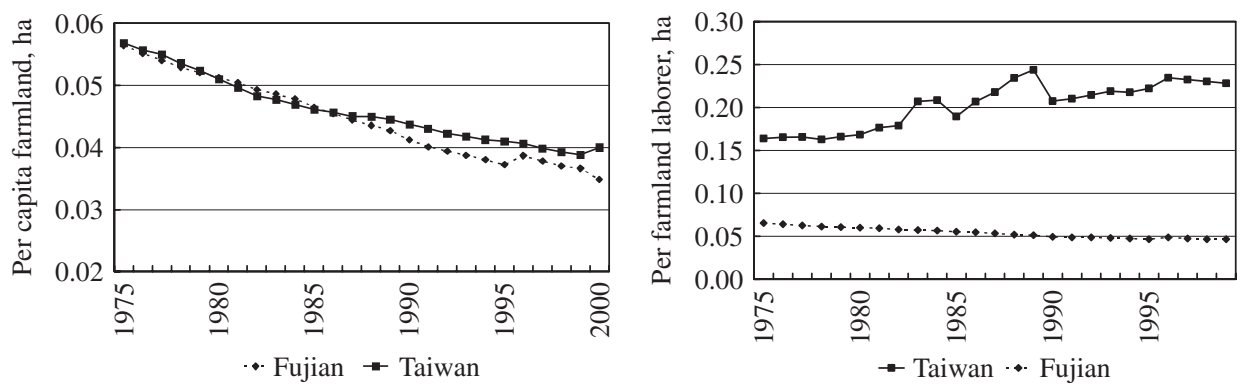

Fig. 3. Comparison between Fujian and Taiwan in area of farmland per capita (left) and per farm laborer (right). 
(2003). CLSI is defined as the ratio of the local average cultivated land productivity to the regional average cultivated land productivity. Another index, standard cultivated land (SCL), can be calculated by multiplying actual cultivated land by CLSI. For our study, we selected rice, a major crop in both Fujian and Taiwan, to calculate CLSI and SCL.

The following illustrates how to derive the change of SCL between 1978 and 2001 for Fuzhou County in Fujian. First, the CLSI can be calculated by dividing the average rice production in Fuzhou by the average rice production in Fujian, with both numbers weighted by their respective multiple cropping indices:

$$
\begin{aligned}
\text { CLSI }_{\text {Fuzhou }} & =(422 \mathrm{~kg} / \mathrm{ha} \times 2.56) /(356 \mathrm{~kg} / \mathrm{ha} \times 2.09) \\
& =1.45 .
\end{aligned}
$$

Then the change of SCL can be calculated by multiplying 1.45 by the change of cultivated land:

$\Delta \mathrm{SCL}_{\text {Fuzhou }}=1.45 \times(-5758 \mathrm{ha})=-8349$ ha.

In the case of Fuzhou, the loss of SCL is higher than the actual loss of cultivated land because of the county's higher productivity relative to other counties in Fujian.

Figs. 4 and 5 plot the local CLSI against the change of cultivated land by county for the past 23 years in Fujian and Taiwan, respectively. Fig. 4 shows that the heavy losses of cultivated land in Fujian have taken place mainly in more productive counties (i.e., higher CLSIs). In contrast, Fig. 5 shows that losses of cultivated land in Taiwan have occurred in average productive counties (i.e., mid-range CLSIs) and, at the same time, increases of cultivated land have occurred at both ends of the CLSIs. Thus the distribution of cultivated land changes has been more balanced relative to agricultural productivity in Taiwan than in Fujian.

Table 1 shows aggregated data by actual area and standard area and by decrease and increase. Because of the steady losses of cultivated land in both regions, the ratio of net decrease of cultivated land to net increase of cultivated land is negative in every case. $(-8.02: 1$ means that the net

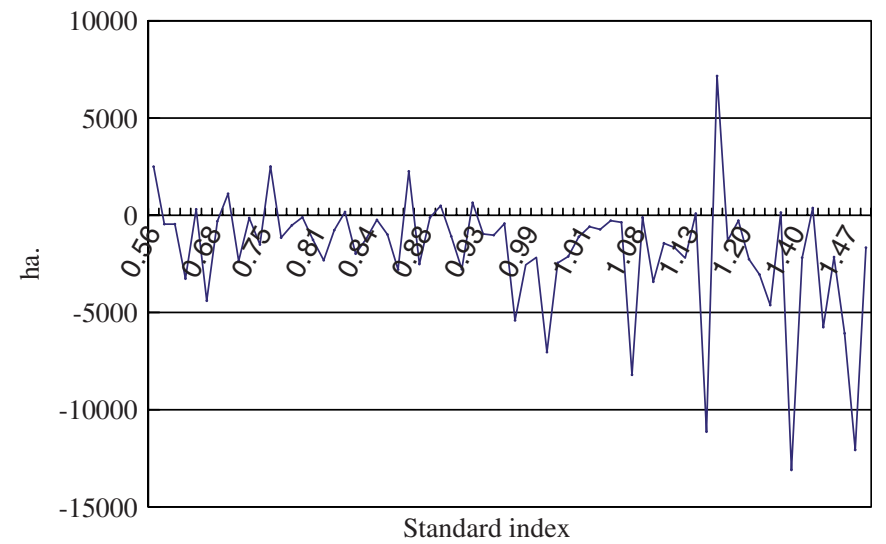

Fig. 4. Cultivated land change against cultivated land standard index (CLSI) by county in Fujian, 1978-2001.

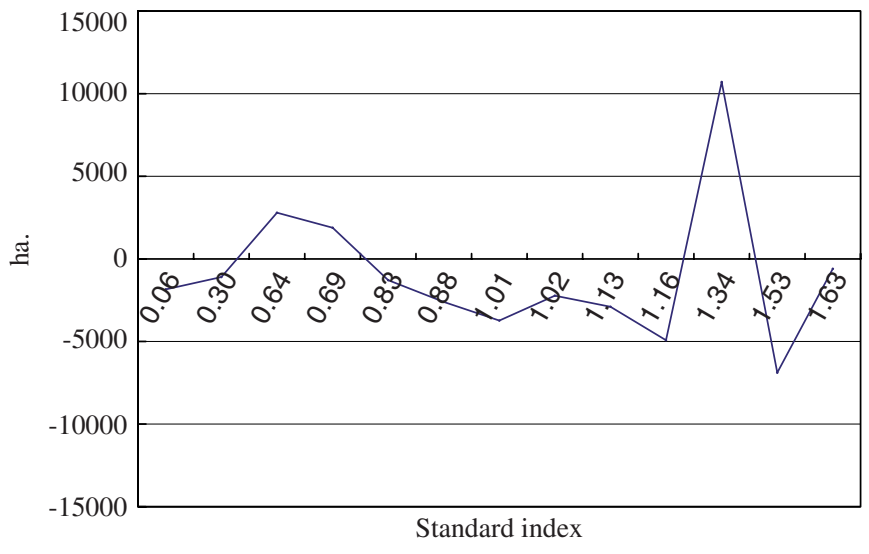

Fig. 5. Cultivated land change against cultivated land standard index (CLSI) by county in Taiwan, 1977-2000.

Table 1

Comparison of standard area change and actual area change of cultivated land in Fujian and Taiwan

\begin{tabular}{lll}
\hline Region & Cultivated land & $\begin{array}{l}\text { Net decrease of cultivated } \\
\text { land: net increase of } \\
\text { cultivated land }\end{array}$ \\
\hline Fujian (1978-2001) & Actual area & $-8.02: 1$ \\
& Standard area & $-9.70: 1$ \\
Taiwan (1977-2000) & Actual area & $-5.22: 1$ \\
& Standard area & $-3.56: 1$ \\
\hline
\end{tabular}

decrease of cultivated land is eight times larger than the net increase of cultivated land.) But the more interesting information can be derived from Table 1 by comparing between actual area and standard area. In Fujian, a decrease of each ha of actual cultivated land equals a decrease of 1.21 ha of SCL $(9.70 / 8.02)$. In other words, newly cultivated land is less productive than the cultivated land lost. The pattern is reversed in Taiwan: a decrease of each ha of actual cultivated land equals a decrease of 0.68 ha of SCL (3.56/5.22). In Fujian, as in other coastal provinces of China, land management policies have not achieved their intended goals of protecting cultivated land (Ho and Lin, 2004; Lin and Ho, 2005). In contrast, farm income enhancement programs in the 1970s and 1980s have indirectly protected productive agricultural land in Taiwan (Chen, 2002).

\section{Causes for cultivated-land changes}

\section{Proximate causes}

This section examines proximate causes that directly impact cultivated land in Taiwan and Fujian. Table 2 shows quantitative changes of cultivated land by land-use type in Taiwan from 1978 to 2000. Reclamation from forest and slope lands, riverside, and tidal land account for the largest percentage (49.54) of the increase in cultivated land. On the other hand, built-up areas have the largest 
percentage (29.85) of the decrease in cultivated land, followed by forestation and fallow (24.90).

Table 3 shows quantitative changes of cultivated land by land-use type in Fujian from 1983 to 2001. Like Taiwan, reclamation account for the largest percentage (64.13) of the increase in cultivated land. But the percentages of tidal land reclamation (30.14) and land renovation (27.87) are much higher in Fujian than in Taiwan. Built-up areas also have the largest percentage (46.95) of the decrease in cultivated land; this percentage is considerably higher than in Taiwan.

When examined by sub-period, Tables 2 and 3 clearly show that the more dynamic (i.e., greater rates of change) sub-period is from 1978 to 1989 in Taiwan and from 1991 to 2001 in Fujian. In Fujian, the increase of cultivated land is $130 \%$ higher between 1991 and 2001 than between 1980 and 1990. Likewise, the decrease of cultivated land is $58 \%$ higher in the second sub-period than the first.

\section{Grey relation analysis}

We used grey relation analysis (GRA) as an exploratory tool to rank the explanatory variables for cultivated land changes in Fujian and Taiwan. The mathematics of GRA is derived from grey theory originally developed by Deng (1985a,b). Often used as an alternative to statistical correlation analysis, GRA does not require assumptions about the statistical distribution of data and can be used with a relatively small amount of data (Chang and Lin, 1999). GRA is therefore ideal for our study considering the problem of data availability. Since the early 1980s, GRA has been applied to various fields including analysis of carbon dioxide emissions, performance of airports, and the form design of mobile phones (Chang and Lin, 1999; Feng and Wang, 2000; Hsu and Chen, 2003; Lai et al., 2004; Wang et al., 2004; Wu et al., 2004; Chang et al., 2005).

Table 2

Quantitative change of cultivated land in Taiwan from 1978 to 2000

\begin{tabular}{|c|c|c|c|c|c|c|c|}
\hline Year & Increase (ha) & \multicolumn{6}{|c|}{ Prcent increase of cultivated land from } \\
\hline 1978-2000 & 251722.74 & 32.49 & 2.98 & 3.19 & 13.86 & 6.69 & 40.79 \\
\hline 1978-1989 & 161439.20 & 36.83 & 3.65 & 3.70 & 13.67 & 4.43 & 37.73 \\
\hline 1990-2000 & 90283.59 & 24.74 & 1.80 & 2.28 & 14.20 & 10.72 & 47.22 \\
\hline & & Built-up & Aquaculture & $\begin{array}{l}\text { Forestation and } \\
\text { uncultivated }\end{array}$ & Loss to disaster & $\begin{array}{l}\text { Re-division and } \\
\text { measure } \\
\text { correction }\end{array}$ & Others \\
\hline 1978-2000 & 327700.85 & 29.85 & 8.72 & 24.90 & 3.07 & 19.95 & 13.51 \\
\hline 1978-1989 & 194503.28 & 24.35 & 9.63 & 29.94 & 2.99 & 20.61 & 12.47 \\
\hline
\end{tabular}

Data source: Taiwan Agricultural Yearbook, 1978-2000.

Table 3

Quantitative change of cultivated land in Fujian from 1983 to 2001

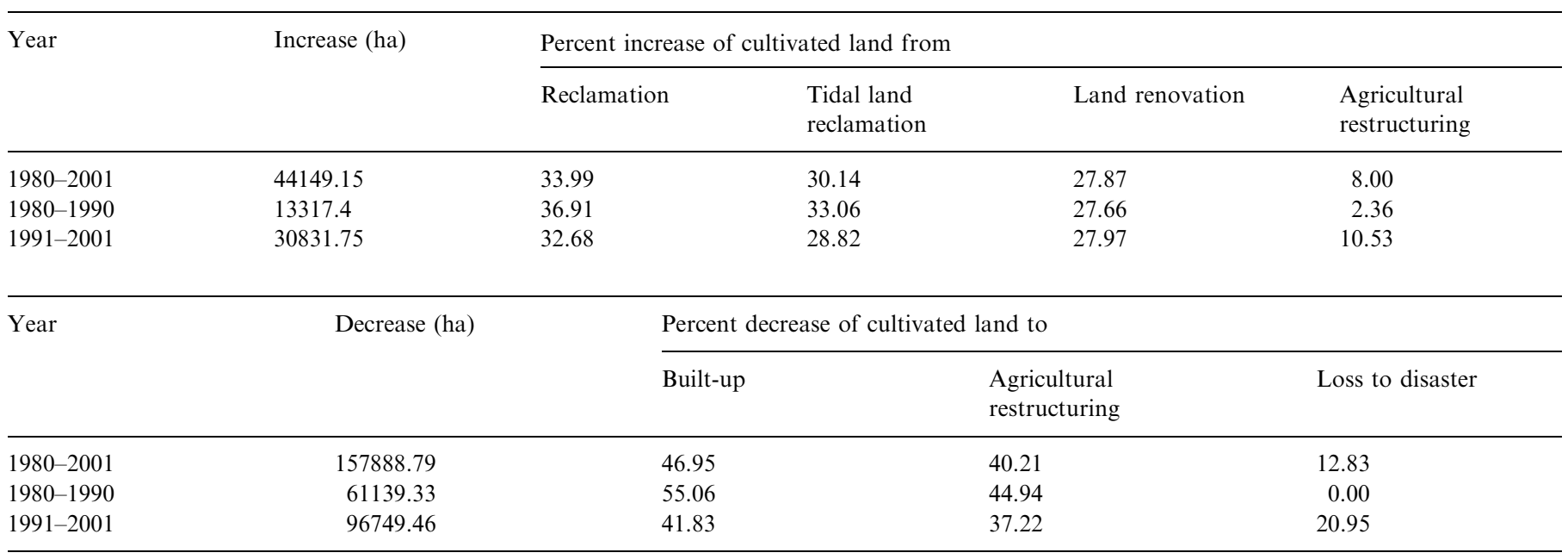

Data source: Fujian Statistical Yearbook, 1983-2001. 
Input variables for GRA are typically organized into categories. For this study, we adopted the following six categories used by Wei and Chen (2004) in their study of nonagricultural use of cultivated land in Fujian: population and urbanization, economic level, primary industry, secondary industry, tertiary industry, and export orientation. We then selected 22 factors in Fujian and 21 factors in Taiwan from available government publications to represent the six categories.

GRA starts with a series of the reference factor and the series of the compared factors. Usually, each series is normalized by dividing respective data of the original series by their averages. Let the transformed reference series be $x_{0}=\left\{x_{0}(1), x_{0}(2), \ldots, x_{0}(n)\right\}$, and the compared series be $x_{i}=\left\{x_{i}(1), x_{i}(2), \ldots, x_{i}(n)\right\}, i=1$ to $m$, where $n$ represents points in a time series and $m$ the number of compared factors. The relational coefficient $\xi_{01}(k)$ between the reference series $x_{0}(t)$ and the compared series $x_{i}(t)$ at time $\mathrm{k}$ can be calculated by the following equation:

$\xi_{01}(k)=\frac{\min _{i} \min _{k}\left|x_{0}(k)-x_{i}(k)\right|+\delta \max _{i} \max _{k}\left|x_{0}(k)-x_{i}(k)\right|}{\left|x_{0}(k)-x_{j}(k)\right|+\delta \max _{i} \max _{k}\left|x_{0}(k)-x_{i}(k)\right|}$,

where $\left|x_{0}(k)-x_{i}(k)\right|$ denotes the absolute difference between the two sequences, $\min _{i} \min _{k}\left|x_{0}(k)-x_{i}(k)\right|$ and $\max _{i}$ - $\max _{k}\left|x_{0}(k) x_{i}(k)\right|$ are the minimum distance and the maximum distance for all time points in all compared sequences, which form a comparison environment, and $\delta$ is a distinguishing coefficient, which is used to adjust the range of the comparison environment and to control the level of differences of the relational coefficients. $\delta$ can range from 0 to 1 but is usually set at 0.5 .

If we assume that every point in a series is equally important, then the series or 'line' relational grade can be obtained by averaging relational coefficients at all time points:

$r_{0 i}=\frac{1}{n} \sum_{k=1}^{n} \xi(k)$

If the relational grade from compared series $i$ is greater than $j$, it means that compared series $i$ has a higher degree of correlation with the reference series than $j$. Therefore, by ordering the relational grades calculated from GRA, we can find the importance ranks of the compared factors.

We ran GRA for each region by sampling data in three sub-periods: 1980-1990, 1991-2001, and 1980-2001 in Fujian; and 1973-1989, 1990-1998, and 1973-1998 in Taiwan. Tables 4 and 5 show the ordered relational grades by factor in Fujian and Taiwan, respectively.

Table 4

Relational grades of change of cultivated land in Fujian with a distinguishing coefficient of 0.5

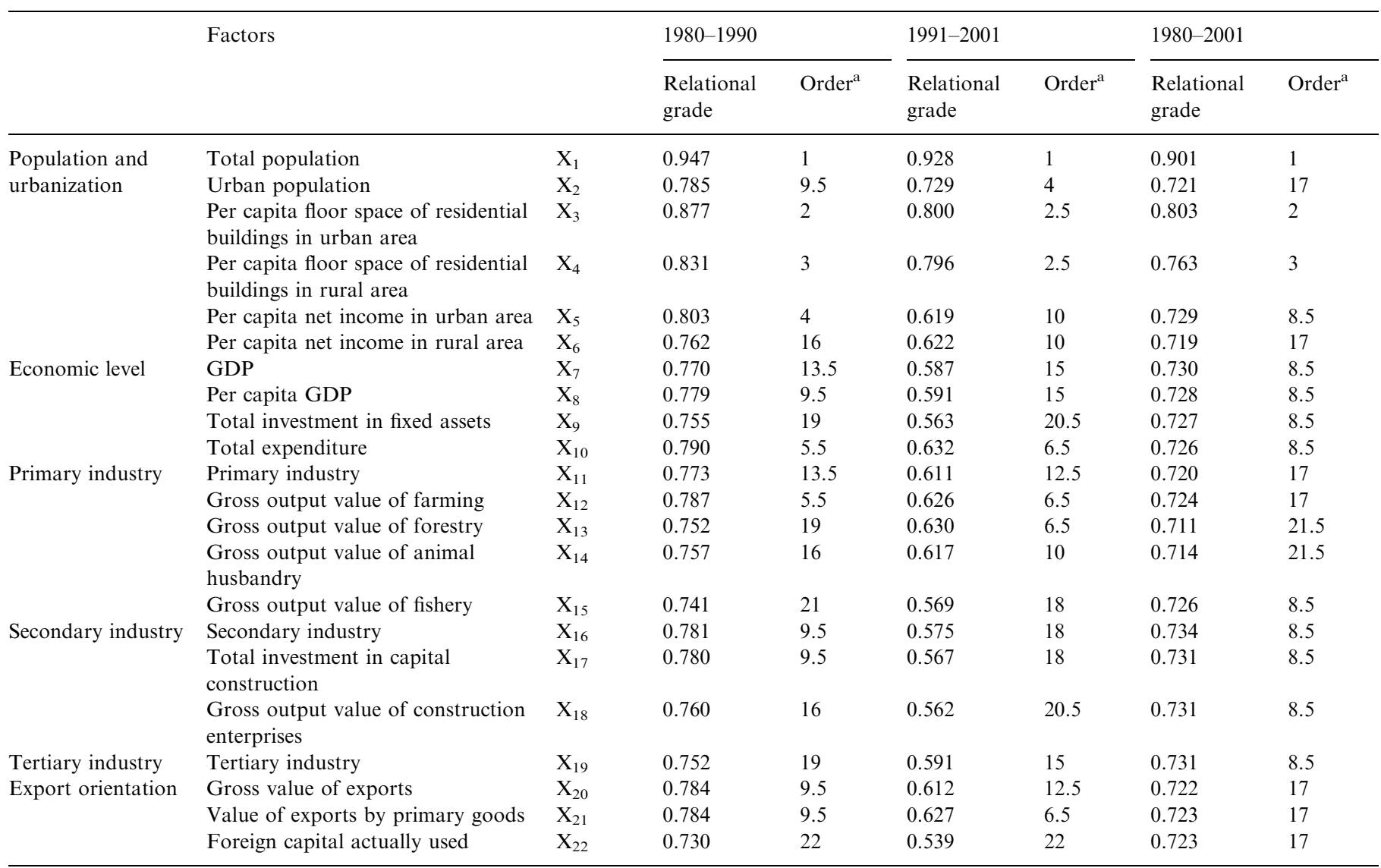

${ }^{\mathrm{a}}$ The rank orders are based on relational grade values with 2 decimal digits. 
As shown in Tables 4 and 5 , the most relevant explanatory variables (driving forces) in both Fujian and Taiwan are total population, per capita floor space, and urban population (1991-2001 in Fujian). It becomes more difficult to order the other driving forces as their importance ranks change over time. In Fujian, the second tier of most relevant factors consists of total expenditure by government and gross output value of farming in 1980-1990. The same two factors are joined by value of exports by primary goods and gross output value of forestry in 1991-2001. In Taiwan, the second tier of most relevant factors in 1973-1989 consists of gross output value of forestry, investment in agriculture, foreign capital actually used, and value of exports by primary goods. In 1990-1998, investment in agriculture is ranked first, gross output value of fishery is ranked third, and other important factors include gross output value of farming and primary industry.

Table 6 shows the ordered average relational grades by category for both regions. Two trends appear in Table 6 . First, the ranking of the average relational grades by category is more stable over time in Taiwan than in Fujian.
The top three categories in Taiwan are population and urbanization, primary industry, and export orientation. In Fujian, only the first ranking of population and urbanization is consistent over time. Second, the closest match between Taiwan and Fujian in terms of the overall ranking is between 1991-2001 in Fujian and 1973-1989 in Taiwan. In other words, the driving forces for cultivated land changes in Fujian in 1991-2001 have the same ranking order of importance as that in Taiwan in 1973-1989.

\section{Discussion and conclusions}

We assumed that similar land-use changes can occur in different regions as the regions pass through comparable stages of economic development at different times. Fujian is behind Taiwan by 15-20 years based on the start of economic development and the occurrence of industrial upgrade. This study found a similar time lag in cultivated land changes: greater rates of changes occurred from 1978 to 1989 in Taiwan and from 1991 to 2001 in Fujian, and the overall ranking of major driving forces for cultivated land changes was the same between Taiwan in 1973-1989 and

Table 5

Relational grades of change of cultivated land in Taiwan with a distinguishing coefficient of 0.5

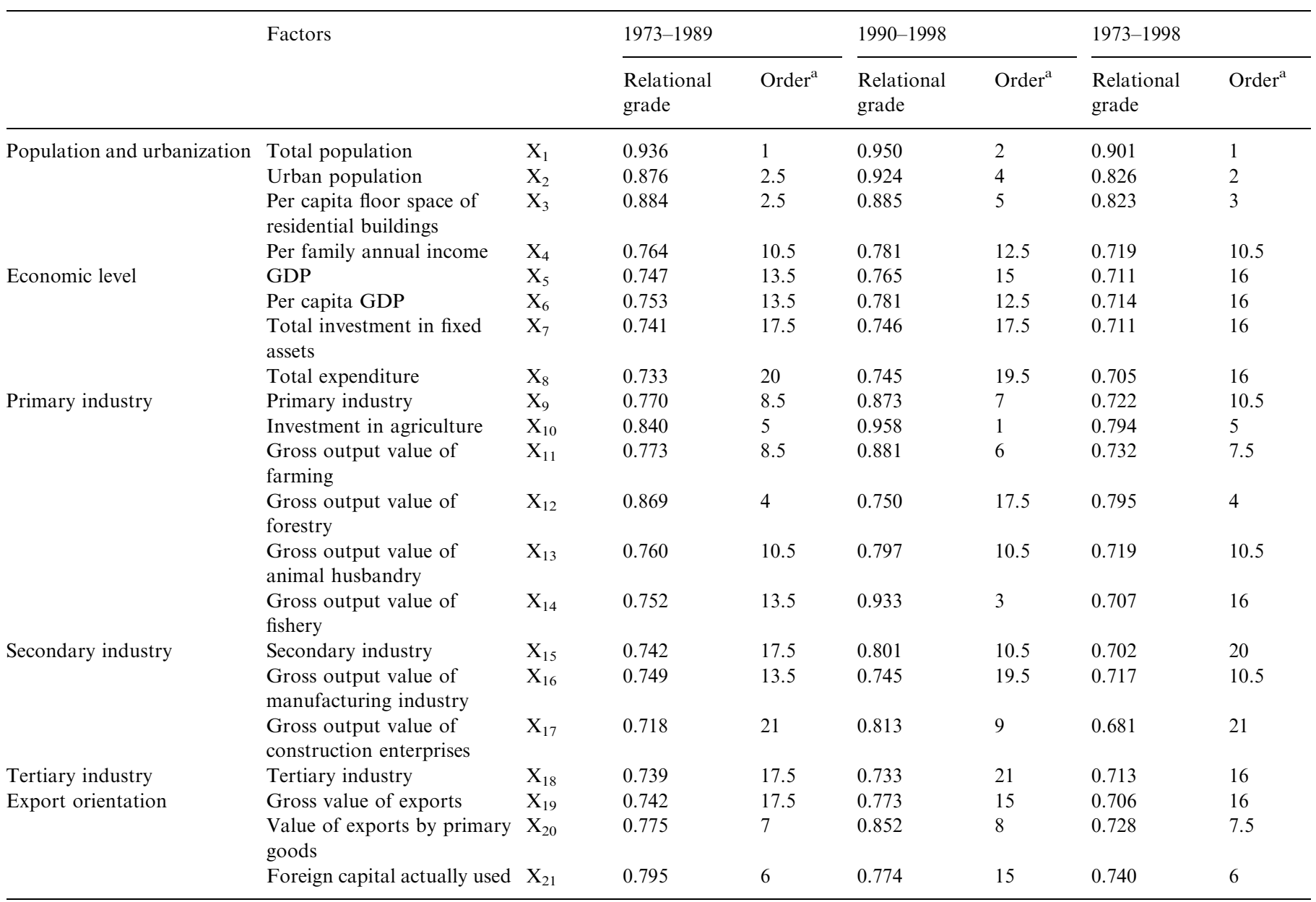

${ }^{\mathrm{a}}$ The rank orders are based on relational grade values with 2 decimal digits. 
Table 6

Average relational grades of change of cultivated land by category in Fujian and Taiwan

\begin{tabular}{|c|c|c|c|c|c|c|c|c|c|c|c|c|}
\hline \multirow[t]{2}{*}{ Year } & \multicolumn{2}{|c|}{$\begin{array}{l}\text { Population and } \\
\text { urbanization }\end{array}$} & \multicolumn{2}{|c|}{ Economic level } & \multicolumn{2}{|c|}{ Primary industry } & \multicolumn{2}{|c|}{ Secondary industry } & \multicolumn{2}{|c|}{ Tertiary industry } & \multicolumn{2}{|c|}{ Export orientation } \\
\hline & $\begin{array}{l}\text { Relational } \\
\text { grade }\end{array}$ & Order & $\begin{array}{l}\text { Relational } \\
\text { grade }\end{array}$ & Order & $\begin{array}{l}\text { Relational } \\
\text { grade }\end{array}$ & Order & $\begin{array}{l}\text { Relational } \\
\text { grade }\end{array}$ & Order & $\begin{array}{l}\text { Relational } \\
\text { grade }\end{array}$ & Order & $\begin{array}{l}\text { Relational } \\
\text { grade }\end{array}$ & Order \\
\hline \multicolumn{13}{|l|}{ Fujian } \\
\hline $1980-2001$ & 0.773 & 1 & 0.727 & 4 & 0.719 & 6 & 0.732 & 2 & 0.731 & 3 & 0.723 & 5 \\
\hline $1980-1990$ & 0.834 & 1 & 0.774 & 2 & 0.762 & 5 & 0.773 & 3 & 0.752 & 6 & 0.766 & 4 \\
\hline 1991-2001 & 0.749 & 1 & 0.593 & 3.5 & 0.611 & 2 & 0.568 & 6 & 0.591 & 5 & 0.593 & 3.5 \\
\hline \multicolumn{13}{|l|}{ Taiwan } \\
\hline 1973-1998 & 0.817 & 1 & 0.710 & 5 & 0.745 & 2 & 0.700 & 6 & 0.713 & 4 & 0.725 & 3 \\
\hline 1973-1989 & 0.865 & 1 & 0.744 & 4 & 0.794 & 2 & 0.736 & 6 & 0.739 & 5 & 0.771 & 3 \\
\hline 1990-1998 & 0.885 & 1 & 0.759 & 5 & 0.865 & 2 & 0.786 & 4 & 0.733 & 6 & 0.800 & 3 \\
\hline
\end{tabular}

Fujian in 1991-2001. Although these results apply only to cultivated land changes, they are encouraging enough that we are already planning to use the same assumption in other comparative case studies involving urban sprawl and specific land uses such as aquaculture.

This study found that Fujian had a greater rate of decline in both cultivated land per farm labor and productive cultivated land than Taiwan. Both phenomena are obviously influenced by land management policies. China's land management policies since the 1980s have been inconsistent and ineffective for protecting productive cultivated land (Cartier, 2001; Lin and Ho, 2003, 2005). But the phenomena can also be related to the level of economic development. For policies such as farm income enhancement and free land market, which have been implemented in Taiwan for years, are not possible at the current level of economic development in Fujian. This study did not examine land management policies as a driving force for cultivated land changes because grey relation analysis cannot accommodate factors that cannot be ranked. An option for examining land management policies as a driving force is to treat them as a dummy variable in regression analysis.

Quantitative data on China's agricultural land can be unreliable and difficult to obtain (Heilig, 1997). For example, 1995 official statistics listed China's arable land total at $95 \mathrm{Mha}$ but more recent estimates have put the total in the range of $130-140$ Mha (Ash and Edmonds, 1998) and even as high as 160 Mha (Smil, 1999). In another example, Yeh and $\mathrm{Li}$ (1997) reported that the loss of agricultural land in a county in Guangzhou was under reported by as much as $61.3 \%$. We also faced a couple of data problems in our study. The use of a new data collection method by the Fujian Province Statistics Bureau made estimates of cultivated land generally higher after 1996. It would be difficult to adjust the before- and after1996 data without direct help from the Bureau. We therefore used the data without adjustment in grey relation analysis. This probably accounted for the generally lower relational grades for 1991-2001 than for 1980-1990 in
Table 4. But because the purpose of grey relation analysis was simply to rank the driving forces for cultivated land changes, this data problem should not affect the results or our interpretation of the results. The time periods for grey relation analysis were not identical between Fujian (1980-2001) and Taiwan (1973-1998) because of incompatible data sources. The problem, however, should not affect our interpretation of the time lag that was based on the sub-periods. As mentioned in the introduction, the practical difficulty in conducting comparative analysis lies in data availability and compatibility. We were able to overcome this difficulty to a large extent by having researchers from both Fujian and Taiwan, but not completely.

\section{Acknowledgments}

The authors wish to thank two anonymous reviewers for their useful comments. Kang-tsung Chang gratefully acknowledges a research grant from the Program for Globalization Studies, Institute for Advanced Studies in Humanities and Social Sciences, National Taiwan University.

\section{References}

Ash, R.F., Edmonds, R.L., 1998. China's land resources, environment and agricultural Production. The China Quarterly 156, 836-879.

Ash, R.F., Qi, L., 1996. The economic challenge. In: Hook, B. (Ed.), Fujian: Gateway to Taiwan. Oxford University Press, Hong Kong, pp. 123-152.

de Brauw, A., Huang, J., Rozelle, K., 2004. The sequencing of reform policies in China's agricultural transition. Economics of Transition 12, 427-465.

Cartier, C., 2001. 'Zone Fever', the arable land debate, and real estate speculation: China's evolving land use regime and its geographical contradictions. Journal of Contemporary China 10, 445-469.

Chang, P., Wang, Y., Tsai, C., 2005. Evolving neural network for printed circuit board sales forecasting. Expert Systems with Applications 29, $83-92$. 
Chang, T.C., Lin, S.J., 1999. Grey relation analysis of carbon dioxide emissions from industrial production and energy uses in Taiwan. Journal of Environmental Management 56, 247-257.

Chen, H., 2002. Policy Option of Taiwans Agricultural Development. International Center for Land Policy Studies and Training, Taoyuan, Taiwan.

Chen, T., Lee, J.S. (Eds.), 2004. The New Knowledge Economy of Taiwan. Edward Elgar, Cheltenham, UK.

Chen, X., 1998. The development of Fujian's outward-oriented economy and its regional differentiation. The Journal of Chinese Geography 8, 311-316.

Clark, C., 1989. Taiwan's Development: Implications for Contending Political Economy Paradigms. Greenwood Press, New York.

Council of Agriculture, 2002. Taiwan Agricultural Yearbook. Taipei, Taiwan.

Deng, J., 1985a. The Grey System-Society and Economy. National Defence Industry Publishing Company, Beijing, China (in Chinese).

Deng, J., 1985b. The Grey Control System. Huzhong Industry College Publishing Company, Wuhan, China (in Chinese).

Edmonds, R.L., 1996. Geography and natural resources. In: Hook, B. (Ed.), Fujian: Gateway to Taiwan. Oxford University Press, Hong Kong, pp. 63-94.

Eng, I., 1997. The rise of manufacturing towns: externally driven industrialization and urban development in the Pearl River Delta of China. International Journal of Urban and Regional Research 21, 554-568.

Fan, C.C., 1995. Of belts and ladders: state policy and uneven regional development in post-Mao China. Annals of the Association of American Geographers 85, 421-449.

Fan, S., Zhang, X., Robinson, S., 2003. Structural change and economic growth in China. Review of Development Economics 7, 360-377.

Feng, C., Wang, R., 2000. Performance evaluation for airlines including the consideration of financial ratios. Journal of Air Transport Management 6, 133-142.

Fujian Province Statistics Bureau, 2002. Fujian Statistical Yearbook. China Statistics Press, Bejing, China (in Chinese).

Geist, H.J., Lambin, E.R., 2002. Proximate causes and underlying driving forces of tropical deforestation. BioScience 52, 143-150.

Gold, T.B., 1986. Taiwan Miracle. M.E. Sharpe Armonk, New York.

Golley, J., 2002. Regional patterns of industrial development during China's economic transition. Economics of Transition 10, 761-801.

Heilig, G.K., 1997. Anthropogenic factors in land-use change in China. Population and Development Review 23, 139-168.

Ho, S.P.S., 1978. Economic Development of Taiwan, 1860-1970. Yale University Press, New Haven, CT.

Ho, S.P.S., Lin, G.C.S., 2004. Converting land to nonagricultural use in China's coastal provinces: evidence from Jiangsu. Modern China 30, 81-112.

Howell, J., 2000. The political economy of Xiamen Special Economic Zone. In: Yeung, Y.M., Chu, D.K.Y. (Eds.), Fujian: A Coastal Province in Transition and Transformation. The Chinese University Press, Hong Kong, pp. 119-142.

Hsu, C., Chen, C., 2003. Applications of improved grey prediction model for power demand forecasting. Energy Conversion and Management 44, 2241-2249.

Johnson, G.E., Woon, Y., 1997. Rural development patterns in postreform China: the Pearl River Delta region in the 1990s. Development and Change 28, 731-751.

Kirkby, R., Zhao, X., 1999. Sectoral and structural considerations in China's rural development. Tijdschrift voor Economische en Sociale Geografie 90, 272-284.

Kuo, S.W.Y., 1983. The Taiwan Economy in Transition. Westview Press, Boulder, CO.

Lai, H., Lin, Y., Yeh, C., 2004. From design of product image using grey relational analysis and neural network models. Computers \& Operations Research 32, 2689-2711.
Li, K.T., 1995. The Evolution of Policy behind Taiwans Development Success. Yale University Press, New Haven, CT.

Lin, C., 1973. Industrialization in Taiwan, 1946-72. Praeger Publishers, New York.

Lin, G.C.S., Ho, S.P.S., 2003. Chinas land resources and land-use change: insights from the 1996 land survey. Land Use Policy 20, $87-107$.

Lin, G.C.S., Ho, S.P.S., 2005. The state, land system, and land development processes in contemporary China. Annals of the Association of American Geographers 95, 411-436.

Lin, J.Y., 1992. Rural reform and agricultural growth in China. American Economic Review 82, 34-51.

Liou, K.T., 1999. Strategies and lessons of China's post-Mao economic development. Policy Studies Review 16, 183-208.

Liu, D., 2002. The Chinese Culture and Community of Fujian and Taiwan Provinces - the Relation Theory of Fujians Culture and Taiwans Culture. Fujian People Publishing House, Fuznou, Fujian (in Chinese).

Maruya, T., 2000. An economic overview. In: Yeung, Y.M., Chu, D.K.Y. (Eds.), Fujian: A Coastal Province in Transition and Transformation. The Chinese University Press, Hong Kong, pp. 169-190.

Oi, J.C., 1999. Rural China Takes Off: Institutional Foundations of Economic Reform. University of California Press, Berkeley, CA.

Otsuka, K., Liu, D., Murakami, N., 1998. Industrial Reform in China: Past Performance and Future Prospects. Oxford University Press, Oxford, UK

Ranis, G., 1979. Industrial development. In: Galenson, W. (Ed.), Economic Growth and Structural Change in Taiwan. Cornell University Press, Ithaca, New York, pp. 206-262.

Smil, V., 1999. China's agricultural land. The China Quarterly 158, 414-429.

Thorbecke, E., 1992. The process of agricultural development in Taiwan. In: Ranis, G. (Ed.), Taiwan: From Developing to Mature Economy. Westview Press, Boulde, CO, pp. 15-72.

Wang, R., Ho, C., Feng, C., Yang, Y., 2004. A comparative analysis of the operational performance of Taiwans major airports. Journal of Air Transport Management 10, 353-360.

Wei, S., Chen, J., 2004. A comparative analysis on non-agriculturalization of cultivated land and relevant factors between Fujian and Taiwan provinces. Journal of Natural Resources 19, 568-576 (in Chinese).

Weng, J., 1994. Economic growth in Fujian Province: A growth center analysis, 1950-91. In: Lyons, T.P., Nee, V. (Eds.), The Economic Transformation of South China: Reform and Development in the Post-Mao Era. Cornell East Asia Program, Ithaca, NY, pp. 89-117.

World Bank, 1993. The East Asian Miracle: Economic Growth and Public Policy. Oxford University Press, New York.

Wu, C., Hsieh, T., Cheng, W., Lu, S., 2004. Grey relation analysis of causes for change orders in highway construction. Construction Management and Economics 22, 509-520.

Yabuki, S., 1995. Chinas New Political Economy: The Giant Awakes. Westview Press, Boulder, CO.

Yeh, A.G., Li, X., 1997. An integrated remote sensing and GIS approach in the monitoring and evaluation of rapid urban growth for sustainable development in the Pearl river Delta, China. International Planning Studies 2, 193-210.

Yeung, Y., 2005. Emergence of the Pan-Pearl River Delta. Geografiska Annaler 87B, 75-79.

Yeung, Y., Chu, D.K.Y., 2000. Fujian: A Coastal Province in Transition and Transformation. The Chinese University Press, Hong Kong.

Zhai, W., Huang, X., 2002. Analysis on the effect of policies operation of cultivated land protection in China. China Land Science 17, 8-13 (in Chinese)

Zheng, H., Feng, Z., 2003. The quantity and quality analysis on dynamic equilibrium of the total cultivated land in China. Resources Science 25, 34-39 (in Chinese). 